\title{
Standard partition coefficients of anionic drugs in the $n$-octanol/water system determined by voltammetry at three-phase electrodes
}

\author{
Géraldine Bouchard, ${ }^{a}$ Alexandra Galland, ${ }^{a}$ Pierre-Alain Carrupt, ${ }^{* a}$ Rubin Gulaboski, ${ }^{b}$ \\ Valentin Mirčeski, ${ }^{b}$ Fritz Scholz ${ }^{b}$ and Hubert H. Girault ${ }^{c}$
}

\author{
a Institut de Chimie Thérapeutique, Université de Lausanne, CH-1015, Lausanne, Switzerland. \\ E-mail: Pierre-Alain.Carrupt@ict.unil.ch \\ ${ }^{b}$ Institut für Chemie und Biochemie, E.-M.-Arndt-Universität, Soldtmannstrasse 23, D-17489, \\ Greifswald, Germany \\ ${ }^{c}$ Laboratoire d'Électrochimie Physique et Analytique, École Polytechnique Fédérale de \\ Lausanne, CH-1015, Lausanne, Switzerland
}

Received 14th April 2003, Accepted 10th July 2003

First published as an Advance Article on the web 31st July 2003

\begin{abstract}
The anionic forms of 26 drugs and organic model compounds have been extensively explored in the $n$-octanol/ water system using voltammetry at three-phase electrodes. The objective of this study was to validate the ability of this electrochemical system to give reliable values of lipophilicity for organic ions, as well as to gain more information on the lipophilic behaviour of anions in the $n$-octanol/water system. Results were used to clarify the solvation mechanisms responsible for ion partitioning and to compare the information obtained in the two solvent systems $n$-octanol/water and 1,2-dichloroethane/water.
\end{abstract}

\section{Introduction}

Although its important role in the pharmacokinetic behaviour of drugs, the partitioning of ions across two immiscible solvents has for a long time been neglected due to the lack of experimental methods well-adapted to its measurement. Classical experimental methods such as potentiometry in biphasic systems or the shake-flask method provide only apparent partition coefficients, not reliable for a use in structure-property relationships since they strongly depend on experimental conditions such as on phase-volume ratio or on supporting electrolytes. ${ }^{1}$ The recent introduction of cyclic voltammetry at the liquid/liquid interface in medicinal chemistry has solved this lack and improved our understanding of the lipophilicity of ions and of their mechanisms of transfer at biphasic interfaces. $^{2}$ Unfortunately, this method requires the use of a polarizable interface, rendering the reference solvent system $n$-octanol/water inadequate.

The $n$-octanol/water partition coefficient $\left(\log P_{\text {oct }}\right)$ has been widely used in quantitative structure-activity relationships (QSAR). It is still extensively employed in pharmacology to predict the bioactivity of drugs and even to drive drug projects, ${ }^{3}$ since it exhibits interesting superficial similarity with lipids: a long alkyl chain plus a functional group having both hydrogen-bond accepting and -donating characteristics.

Recently a new electrochemical methodology has been developed using the oxidation of an electroactive compound dissolved in a droplet of organic solvent, attached to a graphite electrode immersed in the aqueous solution of the respective alkali salts of the studied anions. This approach has been exploited to study the transfer of monoanionic organic compounds ${ }^{4}$ as well as of amino-acids and small peptides ${ }^{5,6}$ across the nitrobenzene/water interface. This methodology was also employed for quantitative chiral recognition of $\mathrm{D}$-and L-amino-acid anion transfer across the chiral, organic liquid/ water interface. ${ }^{7}$ The transfer of the studied ion from the aqueous to the organic phase is driven by the oxidation of the electroactive compound in the droplet in order to maintain the electroneutrality of the organic phase (see Fig. 1). Recently this method was also successfully used to measure for the first time, the standard Gibbs energies of transfer of many inorganic and organic ions at the $n$-octanol/water interface. ${ }^{8}$

In the present work, the anionic forms of 26 drugs and organic model compounds (see Fig. 2), previously extensively studied in the 1,2-dichloroethane/water system, ${ }^{1}$ have been explored using this new electrochemical method in the $n$-octanol/water system. The objective of this study was to validate the ability of this electrochemical system to give reliable values of liphophilicity for organic ions. It was also to gain more information on the lipophilic behaviour of anion in the $n$-octanol/water system in order to clarify the solvation mechanisms responsible for their partitioning and to compare the information obtained in the two solvent systems $n$-octanol/water and 1,2-dichloroethane/water.

\section{Materials and methods}

Compounds and reagents

All the studied compounds were purchased from Fluka (Buch, Switzerland), except sulfinpyrazone (kindly donated

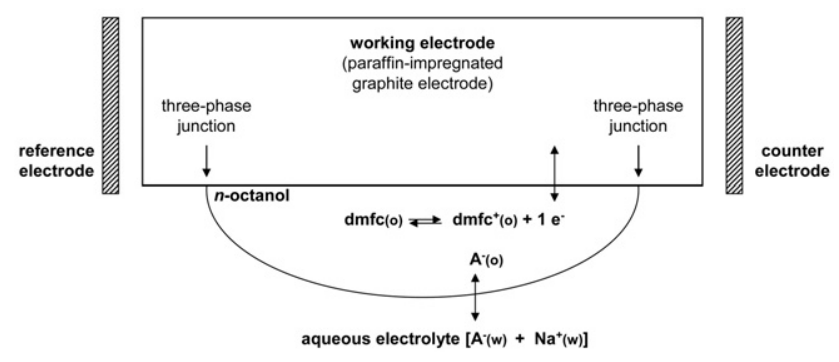

Fig. 1 Scheme of the electrochemical cell. 

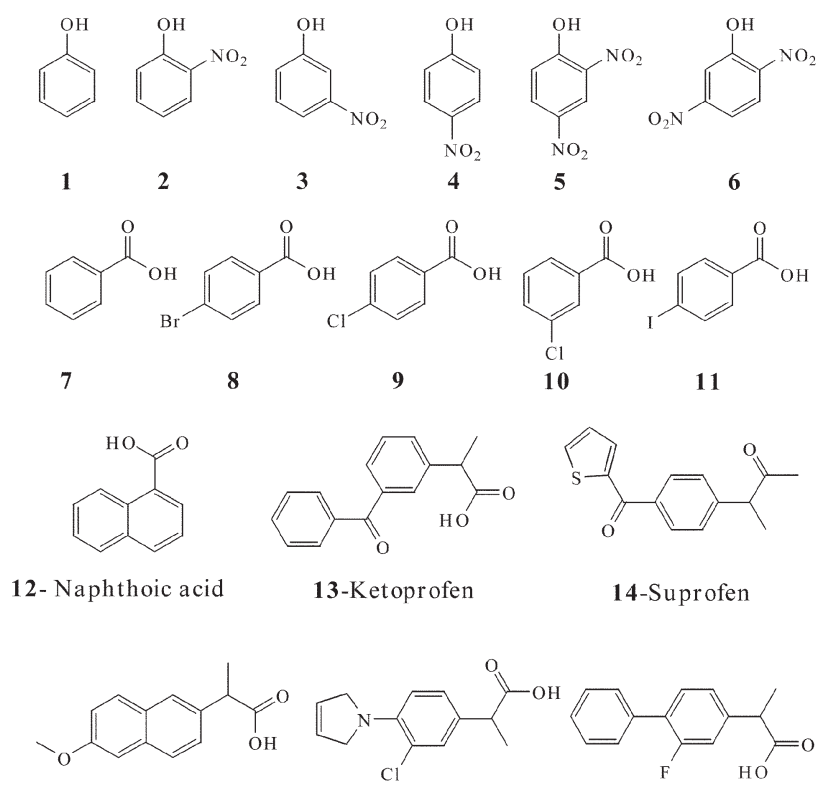

15-Naproxen 16-Pirprofen

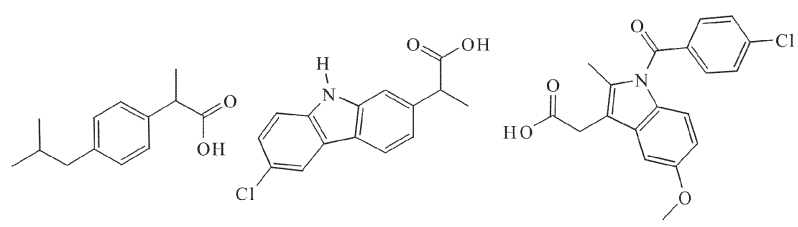

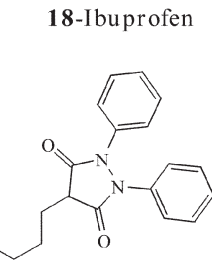

21-Phenylbutazone

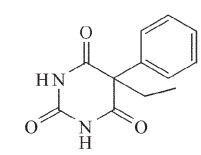

24-Phen obarbital
19-Carprofen

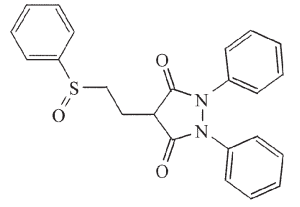

22-Sulfinpyrazone

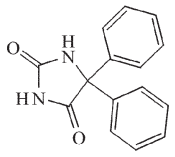

25-Phenytoin
20-Indomethacin

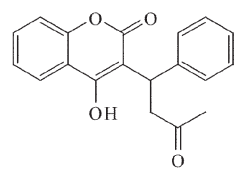

23-Warfarin

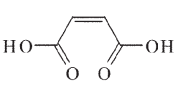

26-Maleic acid
Fig. 2 Chemical structures of the studied compounds.

by Novartis Pharma, Basel, Switzerland). $n$-Octanol was purchased from Acros Organics (Geel, Belgium). All other chemicals were of analytical grade and supplied by Fluka.

\section{Electrochemical method}

A $0.05 \mathrm{~mol} \mathrm{~L}^{-1}$ solution of decamethylferrocene (noted $\mathrm{dmfc}$ ) was prepared by dissolving in water-saturated $n$-octanol. A droplet of this solution $(2 \mu \mathrm{L})$ was attached to the surface of a paraffin-impregnated graphite electrode with the help of an Eppendorf-type pipette and immersed into an $n$-octanol-saturated aqueous solution of 0.01 or $1.0 \mathrm{~mol} \mathrm{~L}^{-1}$ drug dissolved in $1 \mathrm{~mol} \mathrm{~L}^{-1} \mathrm{NaOH}$ or in $0.5 \mathrm{~mol} \mathrm{~L}^{-1}$ buffer of sodium hydrogen phthalate and $\mathrm{HCl}$ (for maleic acid only). ${ }^{9}$

Square-wave voltammograms were recorded using the electrochemical measuring system $\mu \mathrm{AUTOLAB}$ (Eco-chemie, Utrecht, Netherlands). An $\mathrm{Ag} / \mathrm{AgCl} /$ saturated $\mathrm{NaCl}$ solution reference electrode was used and a platinum wire served as auxiliary electrode.

At this stage, it is worth pointing out that the presence of the three-phase junction line in the current set-up is a prerequisite step for following the ion transfer across the $n$-octanol/water interface. Due to the absence of supporting electrolyte in the organic phase, the applied potential can only act at that three-phase boundary line, inducing the electrochemical reaction of dmfc in octanol, simultaneously coupled with the anion transfer across the $n$-octanol/water interface. ${ }^{6}$

At equilibrium, the potential difference $E$ between the carbon and the $\mathrm{Ag} / \mathrm{AgCl}$ electrodes is the sum of the contributions from the redox potential of $\mathrm{dmfc} / \mathrm{dmfc}^{+}$and from the Galvani potential difference at the $n$-octanol/water interface.

$$
E=E_{\mathrm{dmfc}^{+} / \operatorname{dmfc}(\mathrm{o})}^{0}+\frac{R T}{F} \ln \left[\frac{a_{\mathrm{dmfc}^{+}(\mathrm{o})}}{a_{\mathrm{dmfc}(\mathrm{o})}}\right]-\Delta_{\mathrm{o}}^{\mathrm{w}} \phi
$$

where $E_{\mathrm{dmfc}+/ \mathrm{dmfc}(\mathrm{o})}^{0}$ is the standard redox potential of the couple $\mathrm{dmfc}^{+} / \mathrm{dmfc}$ in the organic phase; $F$ is the Faraday constant $\left(96500 \mathrm{C} \mathrm{mol}^{-1}\right), R$ is the gas constant $\left(8.31 \mathrm{~J} \mathrm{~mol}^{-1}\right.$ $\left.\mathrm{K}^{-1}\right)$ and $T$ the temperature in Kelvin; $a_{\mathrm{dmfc}(\mathrm{o})}$ and $a_{\mathrm{dmfc}^{+}(\mathrm{o})}$ are, respectively, the activities of $\mathrm{dmfc}$ and $\mathrm{dmfc}^{+}$in the organic phase; $\Delta_{\mathrm{o}}^{\mathrm{w}} \phi$ is the Galvani potential difference between the aqueous and the organic phases.

Due to the absence of supporting electrolyte in the organic phase, the electrode reaction of the electroactive compound (dmfc) in the organic phase must be accompanied by an anion transfer across the liquid/liquid interface in order to preserve the electroneutrality of the organic phase. When the concentration and the lipophilicity of the studied anion is sufficient, the Galvani potential difference $\Delta_{\mathrm{o}}^{\mathrm{w}} \phi$ is fixed by the partitioning of the anion $\mathrm{A}^{-}$between the aqueous and the organic phase. Then eqn. (1) can be written as follows:

$$
\begin{aligned}
E= & E_{\mathrm{dmfc}^{+} / \mathrm{dmfc}(\mathrm{o})}^{0}+\frac{R T}{F} \ln \left[\frac{a_{\mathrm{dmfc}^{+}(\mathrm{o})}}{a_{\mathrm{dmfc}(\mathrm{o})}}\right] \\
& -\left(\Delta_{\mathrm{o}}^{\mathrm{w}} \phi_{\mathrm{A}}^{0}-\frac{R T}{F} \ln \left[\frac{a_{\mathrm{A}(\mathrm{o})}}{a_{\mathrm{A}(\mathrm{w})}}\right]\right)
\end{aligned}
$$

where $\Delta_{\mathrm{o}}^{\mathrm{w}} \phi_{\mathrm{A}}^{0}$ is the standard transfer potential of the anion $\mathrm{A}^{-}$ from the aqueous to the organic phase, $a_{\mathrm{A}(\mathrm{w})}$ and $a_{\mathrm{A}(\mathrm{o})}$ are the activities of the studied anion in, respectively, the aqueous and organic phases.

The electroneutrality in the organic phase induces eqn. (3).

$$
c_{\mathrm{dmfc}^{+}(\mathrm{o})}=c_{\mathrm{A}(\mathrm{o})}
$$

where $c_{\mathrm{dmfc}^{+}(\mathrm{o})}$ and $c_{\mathrm{A}(\mathrm{o})}$ are, respectively, the concentration of $\mathrm{dmfc}^{+}$and $\mathrm{A}$ in the organic phase.

Then combining eqns. (2) and (3), the formal redox potential $\left(E_{\mathrm{f}}\right)$ of the couple $\mathrm{dmfc}^{+} / \mathrm{dmfc}$ in the organic phase (which corresponds to the equivalent activities of $\mathrm{dmfc}$ and $\mathrm{dmfc}^{+}$) is given by:

$$
E_{\mathrm{f}}=E_{\mathrm{dmfc}^{+} / \mathrm{dmfc}(\mathrm{o})}^{0}+\frac{R T}{F} \ln \left[\frac{a_{\mathrm{dmfc}(\mathrm{o})}^{*}}{2}\right]-\Delta_{\mathrm{o}}^{\mathrm{w}} \phi_{\mathrm{A}}^{0}-\frac{R T}{F} \ln a_{\mathrm{A}(\mathrm{w})}
$$

where $a^{*}{ }_{\mathrm{dmfc}(\mathrm{o})}$ is the initial concentration of dmfc in $n$-octanol.

The absence of kinetic effects regarding the electronic or the ionic transfer allows the assumption that the voltammetric response is under thermodynamic control. ${ }^{9}$ Eqn. (4) shows that in these experimental conditions the formal oxidation potential of dmfc in the organic phase $\left(E_{\mathrm{f}}\right)$ depends on the nature and the concentration of the transferring anion in aqueous phase. The detailed experimental procedure is described elsewhere. ${ }^{9}$

The standard transfer potential $\left(\Delta_{\mathrm{o}}^{\mathrm{w}} \phi_{\mathrm{A}}^{0}\right)$, the standard Gibbs energy of transfer $\left(\Delta G_{\mathrm{tr}, \mathrm{A}}^{0, \mathrm{o}}\right)$ and the standard partition coefficient $\left(\log P_{\text {oct }}^{0, \mathrm{~A}}\right)$ of the studied anion are deduced from the peak potential using eqns. (4), (5) and (6).

$$
\begin{aligned}
\Delta G_{\mathrm{tr}, \mathrm{A}}^{0, \mathrm{w} \rightarrow \mathrm{o}} & =-F \Delta_{\mathrm{o}}^{\mathrm{w}} \phi_{\mathrm{A}}^{0} \\
\log P_{\mathrm{oct}}^{0, \mathrm{~A}} & =-\frac{\Delta G_{\mathrm{tr}, \mathrm{A}}^{0, \mathrm{w} \rightarrow \mathrm{o}}}{2.3 R T}
\end{aligned}
$$




\section{Results and discussion}

The oxidation of $\mathrm{dmfc}$ in the three-phase arrangement $n$-octanol/electrode/water induces a well-defined square-wave voltammetric response with a peak potential depending on the nature and the concentration of the anion in the aqueous phase, confirming the validity of eqn. (4). Fig. 3 shows the square-wave voltammetric response recorded in the $0.1 \mathrm{~mol}$ $\mathrm{L}^{-1}$ aqueous solution of flurbiprofen, 2,5-dinitrophenol, pirprofen, suprofen and $p$-iodobenzoic acid. The peak potential is used to calculate the standard transfer potential, the standard Gibbs energy of transfer and the standard partition coefficient of the studied anion, using eqns. (4), (5) and (6). It is

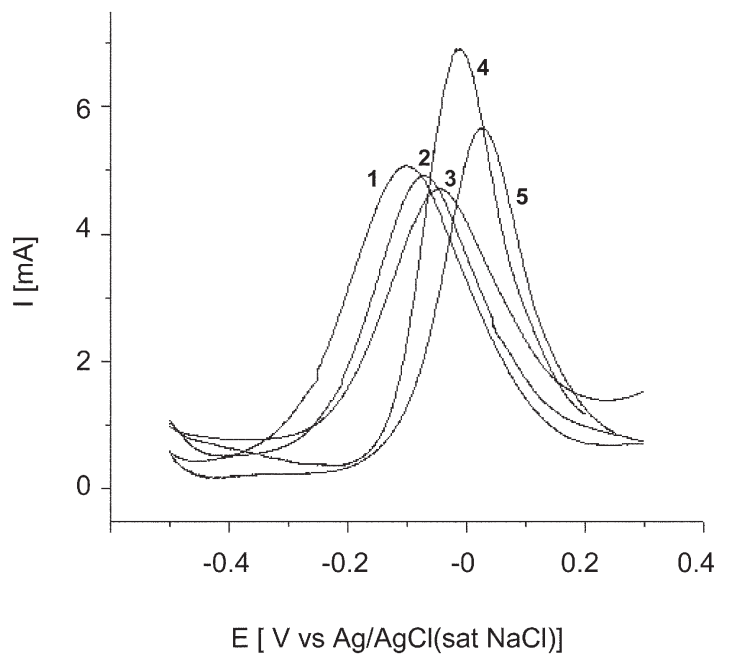

Fig. 3 Square-wave voltammetric responses obtained for mono-anionic (1) flurbiprofen, (2) 2,5-dinitrophenol, (3) pirprofen, (4) $p$-iodobenzoic acid and (5) suprofen $\left(a_{\mathrm{A}(\mathrm{w})}=0.1 \mathrm{~mol} \mathrm{~L}^{-1}\right)$. Squared-wave voltammetry parameters: frequency: $10 \mathrm{~Hz}$, potential step: $1 \mathrm{mV}$, Squared-wave amplitude: $50 \mathrm{mV}$, and starting potential: $-0.5 \mathrm{~V}$. worth noting that four measurements were performed for each concentration of the studied compounds and the mean values of the peak potentials were used for calculating the standard Gibbs energies of transfer. The standard deviation of the peak potentials was $3.6 \mathrm{mV}(n=14)$, which means that the standard deviation of the calculated Gibbs energies of transfer is $0.35 \mathrm{~kJ} \mathrm{~mol}^{-1}$. The results obtained in $n$-octanol/water are given in Table 1; they are compared with results obtained in 1,2-dichloroethane/water system in eqn. (7), from which carprofen (19) is excluded (see explanation below):

$$
\begin{gathered}
\log P_{\mathrm{oct}}^{0, \mathrm{~A}}=0.35( \pm 0.04) \log P_{\mathrm{dce}}^{0, \mathrm{~A}}-3.59( \pm 0.14) \\
n=25 ; r^{2}=0.80 ; s=0.25 ; \quad F=94
\end{gathered}
$$

Fig. 4 shows the very good correlation of the Gibbs free energies of transfer of the studied anions in the two solvent systems and for the five following small inorganic anions: thiocyanate $\left(\log P_{\text {oct }}^{0, \mathrm{~A}}=-5.0, \log P_{\text {dce }}^{0, \mathrm{~A}}=-4.6\right),{ }^{8,10}$ nitrate $\left.\left(\log P_{\text {oct }}^{0, \mathrm{~A}}=-5.9, \quad \log P_{\mathrm{dce}}^{0, \mathrm{~A}}=-5.9\right)^{8,10}\right\}, \quad$ chloride $\quad(\log$ $\left.P_{\text {oct }}^{0, \mathrm{~A}}=-5.8, \log P_{\mathrm{dce}}^{0, \mathrm{~A}}=-6.1\right),{ }^{8,11}$ bromide $\left(\log P_{\mathrm{oct}}^{0, \mathrm{~A}}=-6.3\right.$, $\left.\log P_{\text {dce }}^{0, \mathrm{~A}}=-8.9\right)^{8,11}$ and iodide $\left(\log P_{\text {oct }}^{0, \mathrm{~A}}=-5.2, \quad \log \right.$ $\left.P_{\text {dce }}^{0, \mathrm{~A}}=-4.4\right) \cdot{ }^{8,11}$ Eqn. (8) shows that the introduction of these five inorganic ions does not change noticeably the quality of the statistic parameters, confirming the ability of square-wave voltammetry at the three-phase junction to measure the standard lipophilicity of both small inorganic and large organic anions.

$$
\begin{gathered}
\log P_{\mathrm{oct}}^{0, \mathrm{~A}}=0.33( \pm 0.03) \log P_{\mathrm{dce}}^{0, \mathrm{~A}}-3.67( \pm 0.12) \\
n=30 ; r^{2}=0.84 ; s=0.25 ; F=150
\end{gathered}
$$

These results shows that, for the 30 studied anions, the range of lipophilicity in $n$-octanol/water system $\left(\log P_{\text {oct }}^{0, A}\right.$ between -6.3 and -3.2) is narrower than the range in 1,2-dichloroethane/water $\left(\log P_{\text {dce }}^{0, \mathrm{~A}}\right.$ between -8.9 and -1.5$)$, indicating that the difference of solvation energy of anions between water and $n$-octanol is smaller than the difference between

\begin{tabular}{|c|c|c|c|c|c|c|c|c|c|c|c|c|}
\hline$n$ & Compound & $\Delta_{\mathrm{o}}^{\mathrm{w}} \phi_{\mathrm{oct}}^{0}{ }^{a}$ & $\Delta G_{\mathrm{tr}, \mathrm{A}}^{0, \mathrm{w} \rightarrow \mathrm{oct} b}$ & $\Delta G_{\mathrm{tr}, \mathrm{A}}^{0, \mathrm{w} \rightarrow \mathrm{dce} c}$ & $\log P_{\mathrm{oct}}^{\mathrm{N} d}$ & $\log P_{\mathrm{oct}}^{0, \mathrm{~A} e}$ & $\log P_{\mathrm{dce}}^{\mathrm{N} d}$ & $\log P_{\mathrm{dce}}^{0, \mathrm{~A} d}$ & $\begin{array}{l}\operatorname{diff}(\log \\
\left.P_{\mathrm{oct}}^{\mathrm{N}-\mathrm{A}}\right)^{f}\end{array}$ & $\begin{array}{l}\operatorname{diff}(\log \\
\left.P_{\mathrm{dce}}^{\mathrm{N}-\mathrm{A}}\right)^{f}\end{array}$ & $\begin{array}{l}\Delta \log \\
P_{\mathrm{oct}-\mathrm{dce}}^{\mathrm{N}}\end{array}$ & $\begin{array}{l}\Delta \log \\
P_{\text {oct-dce }}^{\mathrm{A}} g\end{array}$ \\
\hline 1 & Phenol & -244 & 23.5 & 13.1 & 1.46 & -4.1 & 0.61 & -2.3 & 5.6 & 2.9 & 0.85 & -1.8 \\
\hline 2 & 2-Nitrophenol & -236 & 22.8 & 11.4 & 1.77 & -4.0 & 2.81 & -2.0 & 5.8 & 4.8 & -1.04 & -2.0 \\
\hline 3 & 3-Nitrophenol & -247 & 23.8 & 13.7 & 2.00 & -4.2 & 0.92 & -2.4 & 6.2 & 3.3 & 1.08 & -1.8 \\
\hline 4 & 4-Nitrophenol & -259 & 25.0 & 14.2 & 1.96 & -4.4 & 0.72 & -2.5 & 6.3 & 3.3 & 1.24 & -1.9 \\
\hline 5 & 2,4-Dinitrophenol & -253 & 24.4 & 9.7 & 1.37 & -4.3 & 2.46 & -1.7 & 5.7 & 4.2 & -1.09 & -2.6 \\
\hline 6 & 2,5-Dinitrophenol & -264 & 25.4 & 13.1 & 1.75 & -4.5 & 2.49 & -2.3 & 6.2 & 4.8 & -0.74 & -2.2 \\
\hline 7 & Benzoic acid & -341 & 32.9 & 39.5 & 1.96 & -5.8 & 0.72 & -6.9 & 7.8 & 7.6 & 1.24 & 1.1 \\
\hline 8 & 4-Br-Benzoic acid & -293 & 28.3 & 28.5 & 2.86 & -5.0 & 1.04 & -5.0 & 7.8 & 6.0 & 1.82 & 0.0 \\
\hline 9 & 4-Cl-Benzoic acid & -330 & 31.8 & 27.3 & 2.66 & -5.6 & 1.06 & -4.8 & 8.2 & 5.9 & 1.60 & -0.8 \\
\hline 10 & 3-Cl-Benzoic acid & -285 & 27.5 & 28.5 & 2.71 & -4.8 & 0.97 & -5.0 & 7.5 & 6.0 & 1.74 & 0.2 \\
\hline 11 & 4-I-Benzoic acid & -299 & 28.9 & 26.8 & 3.13 & -5.1 & 1.59 & -4.7 & 8.2 & 6.3 & 1.54 & -0.4 \\
\hline 12 & Naphthoic acid & -327 & 31.6 & 27.9 & 3.06 & -5.5 & 1.80 & -4.9 & 8.6 & 6.7 & 1.26 & -0.6 \\
\hline 13 & Ketoprofen & -298 & 28.8 & 22.8 & 2.77 & -5.0 & 2.38 & -4.0 & 7.8 & 6.4 & 0.39 & -1.0 \\
\hline 14 & Suprofen & -335 & 32.3 & 24.5 & 2.83 & -5.7 & 2.36 & -4.3 & 8.5 & 6.7 & 0.47 & -1.4 \\
\hline 15 & Naproxen & -301 & 29.0 & 23.9 & 2.57 & -5.1 & 3.06 & -4.2 & 7.7 & 7.3 & -0.49 & -0.9 \\
\hline 16 & Pirprofen & -301 & 29.0 & 23.9 & 2.78 & -5.1 & 3.58 & -4.2 & 7.9 & 7.8 & -0.8 & -0.9 \\
\hline 17 & Flurbiprofen & -258 & 24.9 & 18.2 & 2.91 & -4.4 & 3.81 & -3.2 & 7.3 & 7.0 & -0.90 & -1.2 \\
\hline 18 & Ibuprofen & -301 & 29.0 & 21.1 & 3.87 & -5.1 & 2.87 & -3.7 & 9.0 & 6.6 & 1.00 & -1.4 \\
\hline 19 & Carprofen & -190 & 18.3 & 20.5 & 4.04 & -3.2 & 2.58 & -3.6 & 6.8 & 5.2 & 1.46 & 0.4 \\
\hline 20 & Indomethacin & -277 & 26.7 & 16.0 & 4.27 & -4.7 & 2.87 & -2.8 & 9.0 & 5.7 & 1.40 & -1.9 \\
\hline 21 & Phenylbutazone & -252 & 24.3 & 9.1 & 3.10 & -4.3 & 4.22 & -1.6 & 7.9 & 6.3 & -1.62 & -2.7 \\
\hline 22 & Sulfinpyrazone & -254 & 24.5 & 9.1 & 3.56 & -4.3 & 4.69 & -1.6 & 7.2 & 6.2 & -1.13 & -2.7 \\
\hline 23 & Warfarin & -242 & 23.4 & 8.8 & 2.70 & -4.1 & 3.62 & -1.5 & 6.9 & 5.4 & -0.92 & -2.5 \\
\hline 24 & Phenobarbital & -322 & 31.1 & 26.6 & 1.44 & -5.5 & 0.71 & -4.7 & 8.1 & 6.5 & 0.73 & -0.8 \\
\hline 25 & Phenytoin & -318 & 30.7 & 27.6 & 2.68 & -5.4 & 1.62 & -4.8 & 7.4 & 6.3 & 1.06 & -0.5 \\
\hline 26 & Maleic acid & -322 & 31.1 & 27.9 & -0.39 & -5.5 & -1.61 & -4.9 & 5.1 & 3.3 & 1.22 & -0.6 \\
\hline
\end{tabular}
1,2-dichloroethane and water. This observation is due to the amphiphatic nature of $n$-octanol, since at $25^{\circ} \mathrm{C}$ the solubility

Table 1 Standard transfer potentials, standard Gibbs energies of transfer and standard partition coefficients 


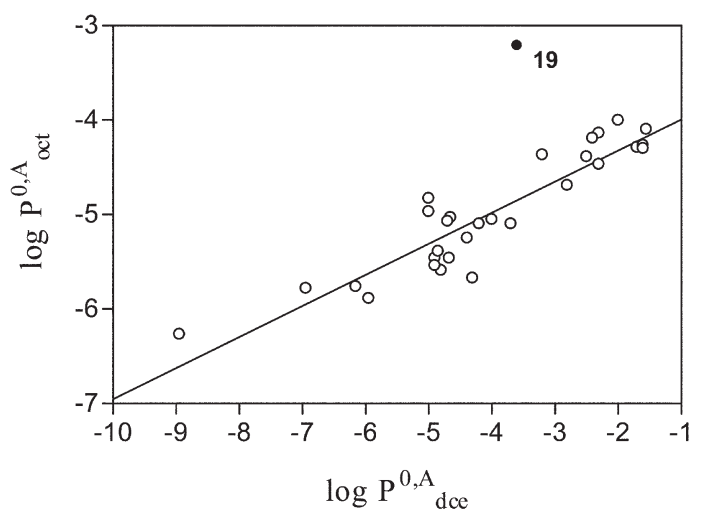

Fig. 4 Relationship between $\log P_{\text {oct }}^{0, \mathrm{~A}}$ and $\log P_{\text {dce }}^{0, \mathrm{~A}}$ values for the 26 compounds of Table 1, as well as for thiocyanate, nitrate, chloride, bromide and iodide anions (values taken from literature ${ }^{8,10,11}$ ).

of water in $n$-octanol may be taken to be 0.275 mole fraction and for $n$-octanol in water, $7.510^{-5}$ mole fraction. ${ }^{12}$ A saturation mole fraction of water in $n$-octanol of 0.275 means that, on average, for every 100 molecules of $n$-octanol there are 38 water molecules present, rendering $n$-octanol relatively hydrophilic. Recent simulations based on continuum solvation models showed that both electrostatic and non-electrostatic terms have a similar contribution to the free energy of solvation of polar solutes, evidencing the balance between hydrophilic and lipophilic characteristics of $n$-octanol as bulk solvent. ${ }^{13}$

Anionic carprofen has a different behaviour than other profen anions, due to its H-bond donor capacity. Its experimental standard lipophilicity in $n$-octanol/water is higher by $1.7 \mathrm{log}$ $P$ units than predicted by eqn. (7), confirming the results obtained for neutral H-bond-donor and non-H-bond-donor compounds. ${ }^{1}$

According to the 2 different potential scales used to calculate the standard transfer potentials (tetraphenylarsonium tetraphenylborate (TATB) assumption for 1,2-dichloroethane/ water, and calibration curve in alcohol/water system for $n$ octanol/water), the absolute values of $\log P$ standard for anions cannot be compared since the $\log P$ scales are different in the two solvent systems.

The strong relationship existing between $\operatorname{diff}\left(\log P_{\mathrm{dce}}^{\mathrm{N}-\mathrm{A}}\right)$ and the delocalization of the negative charge of anions was described in ref. 1. A similar relationship is observed in $n$-octanol/water (see Fig. 5), showing that a strong delocalization of the negative charge (for example, in phenolate) induces a stabilisation of the anion in $n$-octanol and then increases the lipophilicity of the anion. Conversely, for anions with a lessdelocalized negative charge (i.e., benzoic acid), the lipophilicity of the anion decreases.

In conclusion, the present study demonstrated the validity of square-waved voltammetry at a three-phase junction to measure the standard partition coefficients of anionic drugs at the $n$-octanol/water interface. Work is in progress to extend this method to the measurement of cations with the same experimental set-up. The reliability and the simplicity of this approach should be valuable in medicinal chemistry since the understanding of the nature of solute-solvent interactions in

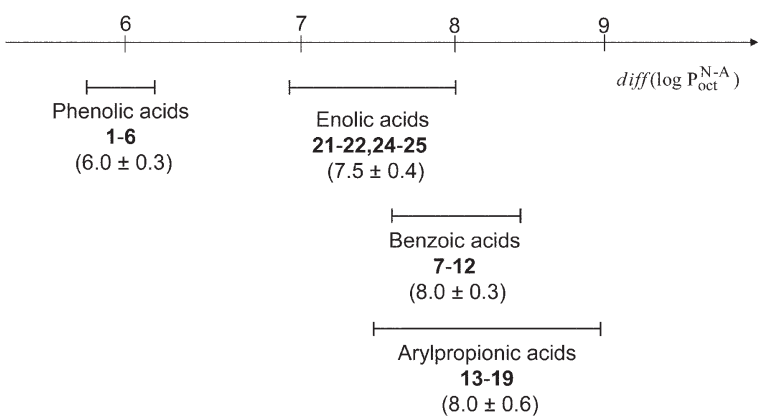

Fig. 5 Schematic representation of the relationship between the parameter $\operatorname{diff}\left(\log P_{\mathrm{N}-\mathrm{A}}^{\mathrm{N}}\right)$ and the ionized functional group. For each functional group, the mean value of $\operatorname{diff}\left(\log P_{\text {oct }}^{\mathrm{N}-\mathrm{A}}\right)$ is given in brackets.

aqueous and organic environments is crucial for the determination of the biological profile of chemical compounds.

\section{Acknowledgements}

G.B. thanks the Fondation du $450^{\text {ème }}$ Anniversaire de l'Université de Lausanne for provision of a research subsidy. P.-A.C., G.B. and H.H.G. are indebted to the Swiss National Science Foundation for support.

R.G. acknowledges Deutscher Akademischer Austauschdienst $(D A A D)$ for providing a $\mathrm{PhD}$ scholarship, and F.S. acknowledges financial support by Deutsche Forschungsgemeinschaft (DFG) and Fonds der Chemischen Industrie (FCI). V.M. thanks Humboldt Foundation for provision of a return scholarship.

\section{References}

1 G. Bouchard, P. A. Carrupt, B. Testa, V. Gobry and H. H. Girault, Chem. Eur. J., 2002, 8, 3478-3484.

2 F. Reymond, G. Steyaert, P. A. Carrupt, D. Morin, J. P. Tillement, H. H. Girault and B. Testa, Pharmacol. Res., 1999, 16, 616-624.

3 A. Leo, C. Hansch and D. Elkins, Chem. Rev., 1971, 71, 525-616.

4 S. Komorsky-Lovric, K. Riedl, R. Gulaboski, V. Mirceski and F. Scholz, Langmuir, 2002, 18, 8000-8005; S. Komorsky-Lovric, K. Riedl, R. Gulaboski, V. Mirceski and F. Scholz, corrections, Langmuir, 2003, 19, 3090.

5 R. Gulaboski, V. Mirceski and F. Scholz, Amino Acids, 2002, 24, 149-154.

6 R. Gulaboski and F. Scholz, J. Phys. Chem. B, 2003, 107, 56505657.

7 F. Scholz, R. Gulaboski, V. Mirceski and P. Langer, Electrochem. Commun., 2002, 4, 659-662.

8 R. Gulaboski, V. Mirceski and F. Scholz, Electrochem. Commun., 2002, 4, 277-283.

9 F. Scholz, S. Komorsky-Lovric and M. Lovric, Electrochem. Commun., 2000, 2, 112-118.

10 B. Hundhammer and T. Solomon, J. Electroanal. Chem. Interfacial Electrochem., 1983, 157, 19-26.

11 A. Sabela, V. Marecek, Z. Samec and R. Fuoco, Electrochim. Acta, 1992, 37, 231-235.

12 J. Sangster, Octanol-Water Partition Coefficients: Fundamentals and Physical Chemistry, Wiley \& Sons, Chichester, 1997.

13 C. Curutchet, M. Orozco and F. J. Luque, J. Comput. Chem., 2001, 22, 1180-1193. 